\title{
СОВРЕМЕННАЯ СИСТЕМА УПРАВЛЕНИЯ \\ ВЗАИМООТНОШЕНИЯМИ С КЛИЕНТАМИ: ФУНКЦИОНАЛЬНЫЕ СЕРВИСНЫЕ ПРИЛОЖЕНИЯ
}

Крайнова Ольга Сергеевна, канд. экон. наук, дои., зав. кафедрой туризма филиала ЧОУВО «Московский университет им. С.Ю.Витте» в г.Нижнем Новгороде, Слаутина Мария Сергеевна, магистрант Мининского университета, 2. Нижний Новгород

Аннотация. В статье представлен обзор современных систем управления взаимоотношениями с клиентами класса CRM. Определены функциональные возможности сервисных приложений для субъектов туристского рынка. Обосновывается необходимость применения в практике деятельности предприятий туриндустрии данных инструментов формирования лояльности туристов, повышения качества обслуживания и построение «прозрачности» бизнес-процессов, в частности, для партнеров.

Ключевые слова: CRM-системы, функциональные сервисные приложения, туристские агентства, туроператорская компания, турист, качество обслуживания, взаимоотношения с клиентами.

На смену традиционным инструментам приходят инновационные технологии. Сфера туризма - не исключение. На сегодняшний день для турфирм актуальным является повышение конкурентоспособности за счёт качества обслуживания и расширения состава предоставляемых услуг.

Итак, автоматизация туристического бизнеса, а именно стратегий взаимодействия с заказчиками (клиентами) оптимизирует маркетинг. До недавнего времени для успешной работы турфирм было достаточно телефона и компьютера с набором элементарных программ и интернетом. Клиент чаще всего приходил сам. А возвращался он или нет - было не столь важно. С увеличением требований клиентов к поставщикам продуктов и услуг, 
развитием самостоятельных поездок и снижением лояльности клиентов пришло и понимание того, что нужно кардинально менять подход.

CRM- Customer Relationship Management (с англ. системы управления взаимоотношениями с клиентами) актуальны особенно сейчас, когда кризис и руководство увольняет людей, а внедрённые системы помогают усилиться и правильно выстраивать бизнес процессы. Целью современных компаний стало снижение оттока старых и приобретение новых клиентов, рост прибыли, полученной от существующих клиентов. Тем более, что клиентская база не сужается, а только расширяется. Клиенты стали тщательнее «считать деньги», торговаться и экономить. Покупательский спрос смещается в сторону более дешевых предложений, клиенты отказываются от сопутствующих товаров: всего дополнительного и необязательного.

До недавнего времени автоматизация работы турагентства начиналась с использования таблиц в «Microsoft Office Exel» для ведения списка заказов и «Microsoft Office Word» - для печати бланков. Для печати шаблонов договоров и кассовых ордеров агентства часто использовали бесплатные программные обеспечения. Недостатки такого подхода - отсутствие возможности совместной работы над файлами и многократный ввод одних и тех же данных. На сегодняшний момент актуальны и востребованы рынком специализированные информационные продукты сопровождения, в частности, CRM-системы, как 1C, Мегатек, МоиДокументы-Туризм, TourManager, amoCRM и т.д.

Практические аспекты внедрения рассмотрены в проводимом исследовании на продуктах различных разработчиков.

Solutions.1c.ru - это peсурс фирмы " $1 C^{\prime \prime}$, на котором собрана информация обо всех отраслевых и специализированных решениях "1C:Предприятие 8"- это автоматизированная система, которая позволяет компании поддерживать взаимоотношения с клиентами, собирать информацию о клиентах и использовать ее в интересах своего бизнеса. 
Основные опции «1C:CRM» включают в себя следующие компоненты CRM-системы:

- управление продажами, маркетингом и сервисом;

- управление бизнес-процессами;

- управление временем;

- интеграция с компьютерной телефонией.

Решения «1C:CRM» интегрируются с системами управленческого учета по платформе «1C:Предприятие 8», что позволяет сотрудникам работать в единой программе без затрат на синхронизацию и обмен данными. «1C:Турагентство 8» - отраслевое решение, предназначенное для автоматизации оперативного и управленческого учета в туристических агентствах.

С точки зрения практического внедрения в работу предприятий туризма и индустрии гостеприимства, основными функциональными возможностями программного продукта являются:

- учет заявок туристов в разрезе направлений, туров, менеджеров;

- работа с пакетными и составными турами;

- генерация печатных форм заявок на тур, договоров с туристами, путевок и счетов на оплату;

- все необходимые данные подставляются из справочников системы;

- функции CRM-системы: учет всех контактов с туристами и туроператорами, отправка e-mail и SMS из программы с фиксацией всех контактов;

- формирование отчетов по заявкам с контролем взаиморасчетов и финансовых показателей по каждой заявке;

- анализ эффективности рекламы;

- бонусная схема работы с рекомендателями турагентства;

- управленческая отчетность позволяет держать под контролем наличие денежных средств турагентства и рентабельность бизнеса. 
Мегатек - компания, основанная в 1996 году и занимающая лидирующую позицию на рынке программного обеспечения для туристического бизнеса. Программный комплекс «Мастер-Агент» предназначен для автоматизации деятельности туристического агентства.

Основные функции программы «Мастер-Агент»:

- формирование путевки любой сложности;

- документооборот;

- проведение взаиморасчетов с клиентами;

- взаимодействие с системами онлайн-бронирования туроператоров и информационно-поисковыми системами;

- организация работы с базой данных клиентов / партнеров, в т.ч. и поставщиков услуг;

- прикладные программы для туризма;

- контроль работы менеджеров/отделов агентства;

- статистическая обработка данных, формирование отчетов.

Программный комплекс «Macmep-Tyр» предназначенный для автоматизации деятельности туроператоров, разрабатывается и поддерживается с 1995 года. Непрерывное развитие "Мастер-Тур" соответствует изменяющимся потребностям туристического рынка. ПК "Мастер-Тур" охватывает все основные аспекты деятельности туроператора - от создания прайс-листа и каталогов до реализации турпродукта, от расчета реальной себестоимости до ведения взаиморасчетов с поставщиками, от оперативного учета до управленческого. При работе с "Мастер-Typ" всегда под рукой вся необходимая информация о клиентах, партнерах и взаиморасчетах с ними.

Функциональные блоки «Мастер-Тур»:

Квотирование. "Мастер-Тур" позволяет вносить квоты на любую услугу, используемую в турах и путевках. Кроме этого, программа позволяет вносить квоты на одну и ту же услугу, предоставляемую разными партнерами, распределять квоту на одну и ту же услугу между агентствами. Также существует возможность заводить квоту на продолжительность услуги и на 
заезд.В экране Квоты имеется возможность дополнительно задать порядок использования квот разного типа на определенный отрезок времени. Можно выделять часть квот на агентство, на продолжительность, на заезд, изменить релиз-период и число мест в квоте.

Конструктор туров - предназначен для формирования пакетов услуг и программ туров, готовых к реализации, калькуляции их стоимости, расчета прибыли, комиссионных и т.д.; причем каждая услуга, например стоимость проживания в отеле, может быть разной и зависеть от принимающего туроператора или даже пакета, в котором проживание в этом отеле используется в композиции с этими услугами и трансфером. Введя цены "нетто" на услуги, изменяя прибыль или цены "брутто", менеджер получает возможность просчитать стоимость собранного блока (тура) на разные сезоны, оценить конкурентоспособность тура и, в итоге, сформировать оптимальный тур. Надо отметить, что программа имеет гибкий аппарат расчета цен, позволяющий различать цены на услуги, продаваемые клиенту в пакете или индивидуально, цены на одни и те же услуги, предлагаемые разными партнерами, а также размер комиссионных, даваемых партнерам при продаже тура.

Реализация турпродукта - быстро составив тур по индивидуальному желанию клиента, введя паспортные данные клиентов, менеджер получает возможность формировать все необходимые для оформления документы (договора, ваучеры, списки туристов, анкеты в посольство и т.д.) автоматически. Все отчеты делаются в формате генератора отчетов "Report Sharp-Shooter", что позволяет легко редактировать их в случае необходимости. Любой Ваш документ можно, при необходимости, отослать в одно или несколько мест в удобное для Вас время.

Работа с партнёрами - позволяет создавать базу данных партнёров. Каждому партнёру можно присвоить определённые признаки, назначить комиссионные, отслеживать срок действия договора. Учитывать работу 
менеджеров агентств, а также переносить сотрудника агентства из одного агентства в другое в случае его перехода на новую работу.

Финансовое состояние - позволяет кассиру распечатывать приходнорасходные ордера, счета-фактуры, различные финансовые и отчетные документы, экспортировать данные с помощью ПК «Мастер-Центр оплат». Экспорт в программу "1C " дает возможность проконтролировать взаиморасчеты с партнерами и оплату клиентами туров, оценить реальное финансовое состояние фирмы в заданный момент времени.

Администратор - организация безопасной работы. Вы можете определить полномочия работы в программном комплексе каждому сотруднику фирмы от определения того, с какими режимами может работать сотрудник, до того, к каким турам, странам или отдельным услугам он имеет допуск. В этой части программы Вы имеете возможность настроить шаблоны выходных документов (отчетов).

Справочный блок - в этом разделе редактируется список стран, городов и отелей. Ваш менеджер может легко добавить новую категорию - любой другой справочник.

Технические характеристики программы «Macmep-Typ»: программа написана в архитектуре клиент-сервер. В качестве сервера базы используется MS SQL Server 2012 . Для разработки клиентской части используются С\# и Centura Team Developer 2000.

МоиДокументь-Туризм - все, что нужно для работы с туристами, успешных продаж и организации туристического бизнеса. Позволяет хранить всю важную информацию и данные по туристам, договорам и оплатам туров, заявкам на подбор туров, финансовые гарантии туроператоров и так далее в электронной системе программы. В программе регистрируются все сотрудники, но у каждого свой личный кабинет для оформления документов. В общем доступе туристическая база, заявки, список туроператоров с их финансовыми гарантиями, календарь. В личном доступе собственно оформленные туры. У каждого менеджера свои. Принцип работы: если турист потенциальный и он 
оставил заявку на подбор тура, то необходимо зайти в раздел «заявки» , «добавить туриста» и внести данные в систему (ФИО, телефон, e-mail, комментарий); если турист постоянный (приобрёл тур), то перейти в раздел «туристы» и заполнить анкету, где информации больше (пол, дата рождения, паспортные данные, адрес). Создание пакета документов: номер договора присваивается автоматически TUR-дата оформления, далее необходимо выбирать туроператора у которого турист приобретает тур, валюту и необходимые документы (договор, заявка, путёвка, приходник). Далее с помощью системного поиска выбирается основной турист (на которого оформляются документы) и остальные туристы, заполняется информационная анкета по деталям тура: дата, время, город, аэропорт вылета и прилёта, трансфер, проживание, страховка. Все данные туристов (ФИО, дата рождения, телефон, адрес, паспортные данные и т.д.) вставляются в анкету автоматически. В конце анкеты указывается дата оформления договора и стоимость тура. После нажатия кнопки «сохранить документы» все выбранные документы автоматически создаются в системе и их можно сохранять на компьютер, просматривать, распечатывать, редактировать.

Специальный модуль «МоиДокументы-Туризм: Избранные туры», который позволяет быстро подбирать совершенно разные туры у разных туроператоров и быстро отправлять их потенциальным или постоянным туристам.

Основные возможности программного продукта:

- единая база туристов и централизованный контроль для сети офисов;

- неограниченные возможности статистики и отчетов;

- быстрый документооборот и удобная CRM;

- полный комплект документовдля туриста за 5-7 минут;

- ускорение Online бронирования туров любого туроператора России;

- возможность работать из любого места и с любого устройства;

- контроль сроков оплат, сдачи документов на визы и т.д.;

- контроль качества работы менеджеров и взаимодействия с туристами. 
TourManager - программный продукт для автоматизации работы турагентства. Программа способна решить весь спектр задач, связанных с документооборотом компании, оформлением сделок и ведением клиентской базы.

Возможности TourManager:

- модуль "Заявки". Этот модуль удобен для обработки пожеланий туристов до заключения с ними договора;

- единая база сделок в рамках одного агентства;

- генерация отчетов, позволяющих оценивать различные аспекты работы;

- база клиентов и контрагентов;

- взаимодействие с поисковой системой TourIndex;

- подбор цены туроператора в режиме реального времени и экспорт параметров заявки в программу;

- внесение данных клиентов из базы программы в форму бронирования поисковой системы.

AmoCRM - это одна из лидирующих CRM для туристических агентств в России. Достаточно просто загрузить Ехсеl-документ с клиентской базой в CRM и начать работать. Единое хранилище данных позволит совершать звонки, автоматизировано отправлять e-mail и sms о ближайших поездках и выгодных предложениях прямо из amoCRM. AmoCRM хранит всю информацию о клиентах, поэтому при каждом их повторном визите нет необходимости уточнять паспортные данные. Система автоматизирует работу менеджеров, делая бизнес более мобильным и эффективным.

Основные возможности программного продукта:

- база данных клиентов, компаний и сделок;

- карточка с подробной информацией;

- воронка продаж;

- задачи и события;

- анализ продаж и отчёты; 
- мобильные приложения;

- интеграция с телефоном;

- интеграция с сайтом;

- расширения и надстройки;

- безопасность и права;

- план продаж.

Таким образом, можно ли все CRM-системы считать универсальными? В каждой ли из них учтены потребности сотрудников от и до? Так, например, очевидно отсутствие «корзины» или «черновика» для автоматического сохранения данных; не все программы интегрируют с социальными сетями; существуют сложности с клиентами, у которых одинаковые фамилии и инициалами в клиентской; не все программы осуществляют перенос (импорт/экспорт) данных из систем туроператоров в агентскую систему и для того, чтобы исправить некоторые даны приходится переоформлять документы, переплачивать и создавать новую заявку; в документальной базе отсутствуют шаблоны документов на возврат денежных средств, рекламаций и так далее.

Тем не менее как же определить эффективность внедрения CRMсистемы? Наиболее распространенными критериями эффективности внедрения CRM-системы являются лояльность клиентов и эффективность взаимоотношений с ними.

Для туриста:

- общение с сотрудниками туристических фирм в системе онлайн;

- небольшое ожидание при оформлении документов на оплату тура в кредит, рассрочку, наличным или безналичным расчётом;

- мультиканальность общения (по средствам смс, электронной почты, социальных сетей);

- получение свежей информации и предложений;

- чувство внимания, заботы и поддержки;

- получение бонусов, скидок, подарков, сюрпризов; 
- формированию единого информационного пространства для синхронизации бизнес-процессов "поставщик - потребитель".

Для туристического предприятия в первую очередь это:

- повышение эффективности работы персонала. В результате проводимого исследования на примере отдельных туристских предприятий, авторами выявлено, что временные затраты персонала на выполнение действий, необходимых для работы с клиентом, при внедрении CRM-системы сокращаются, в среднем, на 20-30\%. Это происходит, в основном, за счет ускорения доступа к информации, автоматизации рутинных операций и сокращения времени на внутренние коммуникации и документооборот;

- устранение потерь клиентов. Благодаря «чистой клиентской базе данных», в которой всегда можно дополнить, обновить или отредактировать необходимую информацию о клиенте; мультиканальности взаимоотношений как с туристами, так и с партнёрами по средствам смс, электронной почты, социальных сетей и так далее; планированию встреч, задач по отношению к клиентам; анализу и учёту обращений клиентов, заказов, продаж, а также выявлению причин ухода/потери клиентов;

- независимость данных от сотрудников. В случае прекращения работы одного сотрудника, можно отследить его действия и передать работу другому сотруднику;

- активное привлечение клиентов, которое осуществляется за счёт размещения информации и рекламы на web-страницах; массовой рассылки информации, предложений, объявлений; за счёт вебинаров, семинаров по искусству общения с туристами и продажи туристических продуктов, услуг; за счёт возможности быстро расширить перечень предлагаемых продуктов и услуг;

- прозрачность работы сотрудников для руководителя, что позволяет отследить нагрузку сотрудников; 
- улучшение имиджевой составляющей компании. Даже в кризисный период CRM-системы позволяют достойно работать с любой информацией и взаимодействовать с клиентами.

Кроме того, к очевидным достоинствам CRM-систем следует отнести: установление близких отношений с клиентом, более упрощенный процесс продаж, появление и выявление новых потенциальных источников дохода и минимальный подготовительный период. В заключении, хотелось бы осветить факт того, что развитие концепции CRM привело к появлению целого ряда направлений, таких как: управление взаимоотношениями предприятий (Enterprise Relationship Management - ERM), управление активами клиентов (Customer Asset Management - CAM), автоматизация маркетинга (Marketing Automation - MA), управление технологически ориентированными взаимосвязями (Technology-Enabled Relationship Management - TERM).

\section{Список источников}

1. Головченко В.А. CRM-системы в туристическом бизнесе [Электронный pecypc] // URL:http://tursite.org/modules/TSArticlesExt?csPageId=19 (дата обращения: 19.11.2015).

2. Информационные материалы официального сайта компании «Мегатек»специальные программы для туризма [Электронный ресурс] // URL:http://www.megatec.ru/ (дата обращения: 12.11.2015).

3. Информационные материалы официального сайта разработчика программного продукта 1C [Электронный ресурс] // URL: http://www.1c.ru/rus/firm1c/firm1c.htm (дата обращения: 17.11.2015).

4. Информационные материалы официального сайта разработчика программного продукта 1C [Электронный ресурс] // URL: http://solutions.1c.ru/crm (дата обращения: 19.11.2015).

5. Информационные материалы официального сайта разработчика программного продукта Мои документы [Электронный ресурс] // URL:http://www.moidokumenti.ru/?yclid=5930890953994053545 （дата обращения: 18.11.2015).

6. Информационные материалы официального сайта разработчика программного продукта amoCRM туризма [Электронный ресурс] // URL:http://www.amocrm.ru/ (дата обращения: 10.11.2015). 
7. Кадыков M.В. Методика расчета эффективности внедрения CRM-системы [Электронный pecypc] // URL:http://www.crm-practice.ru/articles/693/ (дата обращения: 19.11.2015).

8. Кузнецов О.В. Системы автоматизации турфирм: вчера, сегодня, завтра [Электронный pecypc] // URL: http://pro.tonkosti.ru/ittehnologii_v_turizme/sistemy_avtomatizatsii_turfirm_vchera_segodnya_zavtra31135061 (дата обращения: 12.11.2015).

9. Рамзаев M. CRM - управлениеотношениями с клиентами [Электронный pecypc] // URL: http://hr-portal.ru/article/crm-upravlenie-otnosheniyami-sklientami (дата обращения: 19.11.2015).

10.Тенденции российского рынка CRM-систем [Электронный ресурс] // URL: http://tadviser.ru/a/146270 (дата обращения: 11.11.2015). 